\title{
Effects of white noise auditory stimulus on stability and balance in sit-to-stand and standing motion of chronic stroke patients
}

\author{
Hee-sung Lim¹, Sang-heon Park ${ }^{1}$, \& Joo-Nyeon Kim²* \\ ${ }^{1}$ Korea National Sport University $\&{ }^{2}$ Korea Institute of Sports Science
}

\begin{abstract}
[Purpose] The purpose of this study was to investigate the effect of auditory stimulus using white noise on stability and balance during sit-to-stand and standing tasks of chronic stroke patients. [Methods] Eighteen chronic stroke patients participated in this study. They asked to perform the tasks of sit-to-stand, standing with eyes open and standing with eyes closed before and after listening to white noise. Eight infrared cameras and one force plate were used to evaluate the stability and balance before and after the white noise stimulus during each task. [Results] There was no significant difference between before and after white noise stimulus in all tasks. On the other hand, the anteroposterior range of $\mathrm{CoP}$ was significantly decreased after white noise stimulus in standing with eyes-closed $(p<.05)$, and the sagittal angle of CoP-CoM was significantly decreased after white noise stimulus in standing with eyes-open and eyes-closed $(p<.05)$. [Conclusion] Auditory stimulus using white noise improves the balance of chronic stroke patients. Therefore it is thought to be helpful for the independent daily life of chronic stroke patients.
\end{abstract}

Key words: Stroke patients, White noise, Auditory stimulus, Stability, Balance

\section{서 론}

뇌졸중(stroke)은 전 세계적인 주요 건강문제 중 하나 로써, 매년 약 1 천 5 백만 명의 환자를 발생시키고, 이 중 5 백만 명이 사망에 이르게 되며 5 백만 명이 영구적인 장 애를 지닌 상태로 삶을 살게 될 만큼 심각한 중추신경계 질환이다(Nadeau, Betschart, \& Bethoux, 2013). 뇌 졸중 환자들은 뇌졸중의 발병 후 혈액이 정상적으로 뇌에 공급되지 않아 뇌 손상에 의한 신체적·심리적 장애를 경 험하게 되며(Peurala, Könönen, Pitkaenen, Sivenius,

논문 투고일 : 2020. 07. 16.

논문 수정일 : 2020. 08. 17.

게재 확정일 : 2020. 09. 09.

* 교신저자 : 김주년(jnkim@kspo.or.kr).

* 이 논문은 2018년 한국연구재단 신진연구자지원사업의 지원을 받아 수행된 연구임(2018S1A5A8028944)
\& Tarkka, 2007; Sheean, 2002; Sheean \& McGuire, 2009), 신체적 장애는 편마비를 동반한 균형 능력의 저하, 비정상적인 보행, 신체 불균형 등으로 인한 기능적 문제를 발생시키게 된다(Krawczyk, Szczerbik, \& Syczewska, 2014).

뇌졸중 환자들에게 있어서 이동과 관련한 기능적인 움 직임은 재활의 최종적인 목표가 되며 (Macko et al., 2002), 이는 뇌졸중 환자들이 뇌졸중 전과 같이 신체의 정상적인 회복이 이루어지지 않게 될지라도, 누군가로부 터의 보조 없이 독립적인 이동이 가능해지면 일상으로의 복귀가 가능해지기 때문이다(Dovat et al, 2008). 그럼 에도 불구하고, 많은 뇌졸중 환자들은 걷기의 근간이 되 는 매우 중요한 자세인 서있는 자세는 물론, 앉아 있는 자 세에서 조차 불안감을 가지고 살아간다(Genthon et al., 2007). 이러한 불안감은 움직임에 대한 불편함과 시각, 
청각 및 고유수용성 등과 같은 감각적 요소의 수용능력 결여가 그 원인이 되며, 나아가 낙상과 같은 이차적인 상 해의 위험성까지 높일 수 있는 요인으로써 영향을 줄 수 있다(Silver, Macko, Forrester, Goldberg, \& Smith, 2000).

지금까지 다양한 선행연구들을 통하여 뇌졸중 환자들 의 기능적인 움직임에 대한 문제점을 밝히고, 이를 향상 시키기 위한 노력이 계속되어왔다. Genthon 등 (2007) 은 뇌졸중 환자들의 앉은 자세와 관련한 연구에서 뇌졸중 환자들은 일반 노인과 비교하여 앉은 자세에서의 압력중 심점(center of pressure $[\mathrm{CoP}]$ )의 변동면적(sway area)이 크고, 속도(velocity)가 빠르게 나타났으며 이는 자세제어 능력의 저하 때문이라고 설명하였다. 또한, Nadeau 등 (2013)은 뇌졸중 환자들의 보행 능력과 관련 된 연구에서 뇌졸중 환자들은 일반 노인과 비교하여 느린 속도로 보행을 수행하며 비대칭적인 움직임과 더불어, 마 비측 하지의 낮은 모멘트(moment)와 파워 (power)를 나 타낸다고 하였다. 그리고 Buurke 등 (2008)은 뇌졸중 환자들을 대상으로 보행 트레이닝을 실시한 연구에서, 보 행을 통한 트레이닝은 뇌졸중 환자들의 마비측에 기능적 인 움직임에 있어서 긍정적인 효과를 줄 수 있다고 보고 하면서, 트레이닝 시 비마비측에 의존한 보행의 형태가 과도하게 발생하지 않도록 주의할 필요가 있다고 보고하 였다. 이처럼 다양한 선행연구를 통해 뇌졸중 환자의 움 직임의 특성과 그 형태를 파악하고, 이를 개선하기 위한 노력은 계속되어 왔다.

이와 비슷한 맥락으로, 많은 선행연구들에서는 뇌졸중 환자의 기능적 움직임을 개선하기 위한 근력 트레이닝과 실제 움직임과 유사한 동작을 활용한 기능적 트레이닝 외 에도, 청각 및 시각 등과 같은 감각 자극(sensory stimulus)이 긍정적인 효과를 나타낼 수 있다고 제시해 왔다(van Vilet \& Wulf, 2006). Thaut과 Abiru (2010)는 리드미컬(rhythmical)한 청각 자극을 동반한 보행 훈련이 뇌졸중 환자들의 보행 능력에 도움을 줄 수 있다고 보고하였고, Cha, Kim과 Chung (2014)은 이와 같은 청각 자극을 이용한 리듬 트레이닝이 뇌졸중 환자들 의 보행속도 및 대칭성의 개선을 가져다 줄 수 있다고 보 고하기도 하였다. 또한, Antić 등 (2008)은 청각 자극이 대뇌의 인지를 담당하는 영역에 자극을 주어 긍정적인 효 과로서 뇌 활동에 영향을 주며 그 밖에 신체의 신진대사
의 변화와 혈액 순환과도 높은 상관이 있다고 보고 하였 다. 이와 같이 청각 자극은 직접적인 근력 및 움직임을 통 한 트레이닝과 같이, 뇌졸중 환자의 기능적인 움직임에 긍정적인 효과를 줄 수 있다고 보고되어지고 있다. 그러 나 뇌졸중 환자들을 대상으로 청각 자극을 실시한 대부분 의 선행연구들은 리듬과 관련한 청각 자극만을 중재 방법 으로 활용하고 있었으며, 청각 자극을 제공할 때 그 소음 의 종류를 고려한 연구는 전무한 실정이다(Cha et al., 2014; Song, \& Ryu, 2016; Ko, Lee, \& Song, 2016; Mainka, Wissel, Völler, \& Evers, 2018).

소음(noise)이란, 일반적으로 과업을 수행하는데 있어 서 해로운 영향을 준다고 알려져 있는 잡음이다 (Söderlund, Sikström, Loftesnes \& Sonuga-Barke, 2010; Helps, Bamford, Sonuga-Barke \& Söderlund, 2014). 그러나 최근 비선형 공명 및 도파민 분비와 관련 하여 특정 소음의 종류가 긍정적인 영향들이 보고되면서 이에 대한 관심이 증가하고 있다(Hwang, $\mathrm{Li}, \mathrm{Wu}$, Chen \& Liu, 2007; Carlson, Rämä, Artchakov \& Linnankoski, 1997; Herweg \& Bunzeck, 2015). 그 중, 백색소음(white noise)은 주파수와 파워 스펙트럼 (20-20,000 Hz)이 일정하고, 반복적으로 발산하는 소음 으로, 인지·집중·수면 등 인간의 과제 해결 능력 및 삶의 질 개선을 위해 다양한 분야에서 사용되어 왔다(Carter, 2013). 집중력과 관련한 문제를 해결하고, 시각과 같은 인지적인 정보를 탐지하는데 도움을 줄 수 있다고 보고되 었으며 (Söderlund et al., 2010), 인지와 관련한 움직임 혹은 다중 과제를 수행함에 있어서도 긍정적인 영향을 미 칠 수 있다고 보고되었다(Carlson et al., 1997). Herweg와 Bunzeck (2015)는 백색소음이 인지 및 지각 능력에 미치는 영향을 살펴본 연구에서 백색소음을 이용 한 청각 자극이 인지 및 운동 기능을 향상시키고, 움직임 에 대한 실수(error)를 줄여줄 수 있다고 보고하였으며, Helps 등 (2014)은 백색소음이 인지 행 동에 미치는 영향 에 관한 연구에서 백색소음의 강도에 따라 그 효과는 다 를 수 있으나 인지적인 정보의 습득을 위한 집중력 향상 과 정확도 증가 효과가 있으며 운동 기능에 까지 긍정적 인 영향을 미칠 수 있다고 보고 하였다.

이와 같은 백색소음의 효과는 시각, 청각 및 고유수용 감각 등과 같은 감각적 요소의 결여로 인하여 기능적 움 
직임에 어려움을 겪고 있는 뇌졸중 환자들에게도 긍정적 인 영향을 미칠 수 있을 것으로 생각된다. 그러나 이와 같 은 긍정적인 효과에도 불구하고, 뇌졸중 환자들의 움직임 을 개선하기 위한 선행연구들에서는 근력 및 실제 움직임 과 유사한 동작을 통한 트레이닝만이 이루어지고 있으 며, 청각 자극을 활용한 연구들에서는 리듬과 관련한 자 극이 대부분을 차지하고 있어 정작 근본적인 소음의 종류 에 해당하는 백색소음이 뇌졸중 환자들의 기능적 움직임 에 미치는 영향을 살펴본 연구는 전무한 실정이다.

따라서 본 연구의 목적은 백색 소음을 이용한 청각 자 극이 만성 뇌졸중 환자의 이동과 관련한 기능적인 움직임 의 근간이 되는 앉았다 일어서기(sit-to-stand [STS]) 및 서있기(standing) 동작 시 안정성과 균형성에 미치는 영향을 과학적으로 살펴보고, 뇌졸중 환자의 최종적인 재 활 목표인 기능적인 움직임의 향상을 위한 정량적인 정보 를 제공하는데 있다.

\section{연구방법}

\section{연구대상}

본 연구의 연구대상자는 경기도 소재의 장애인 복지관 에 소속되어 있는 편마비 진단을 받은 후 1년 이상이 경 과한 오른쪽 편마비, 뇌졸중 환자 18명 (age: $60.28 \pm 9.29$ yrs., height: $164.47 \pm 7.61 \mathrm{~cm}$, weight: $61.21 \pm 9.64 \mathrm{~kg}$, time post-stroke: $11.44 \pm 5.00 \mathrm{yrs}$.) 으로 선정하였다. 모든 연구대상자는 보조기구를 사용하 지 않고 앉았다 일어서기가 가능한 자로 선정하였다. 또 한, 시각과 청각의 기능적 장애 혹은 어지러움증, 전정기 관의 문제가 있는 자 그리고 정형외과적 질환이나 심호흡 계 질환이 있는 자는 연구대상자에서 제외하였다. 본 연 구는 서울시 $\mathrm{K}$ 대학교 연구 윤리위원회의 승인을 받아 실 시되었으며, 모든 대상자는 실험 전, 충분한 설명과 함께 자발적으로 동의서를 작성하였다.

\section{실험절차 및 자료처리}

본 연구는 백색 소음을 이용한 청각 자극이 만성 뇌졸
중 환자의 앉았다 일어서기 및 서있기 동작 시 안정성과 균형성에 미치는 영향을 알아보기 위해 실시되었다. 백색 소음을 이용한 청각 자극은 백색 소음을 제외한 소리를 차단한 환경에서 20 분간 청취하도록 하였으며, 청각 자 극에 대한 효과를 보다 높이기 위해 시야를 차단하는 광 안경을 착용하도록 하였다. 이때, 청각 자극을 위하여 (주)지오앰씨의 엠씨스퀘어(MC square) X7 제품이 실 험에 활용되었다. 이 제품은 6 개의 프로그램과 6 개의 자 연의 소리를 사용자가 임의로 혼합하여 사용할 수 있도록 설계되어 있으며, 본 연구에서는 특정 프로그램과 6 개의 자연의 소리를 혼합하여 사용하였다. 본 연구에서 활용된 프로그램은 알파파와 베타파를 조절하여 주의력과 관심 집중의 정도를 조정하는 특징을 가지고 있다. 각 대상자 는 총 46 개의 반사 마커를 전신에 부착하고, 백색 소음을 청취한 전·후 앉았다 일어서기(STS) 2회와 눈뜨고 (eye-open), 눈감고(eye-closed) 서있기 동작을 각각 10 초 동안 실시하였다. 백색소음의 적용과 각 과제와 수 행순서는 사전 측정에 의해 나타나는 오류를 보완하기 위 해, 무작위로 선정하여 실시하였다.

대상자의 동작에 대한 운동학, 운동역학적 자료는 취 득하기 위하여 8대의 적외선 카메라(Oqus $300^{+}$, Qualysis, Sweden; Sampling rate: $100 \mathrm{~Hz}$ )와 1대의 지면반력기(AMTI, BP12001200-2000, USA; Sampling rate: $1000 \mathrm{~Hz}$ )가 사용되었다. 추출된 3차원 위치데이터는 Butterworth $2^{\text {nd }}$ order low-pass filter를 사용하여 노이즈(noise)를 제거하였으며 이때, 차단주파 수(cut-off frequency)는 $6 \mathrm{~Hz}$ 로 설정하였다.

\section{분석변인}

본 연구에서는 백색 소음을 이용한 청각 자극이 만성 뇌졸중 환자의 앉았다 일어서기 및 서있기 동작 시 안정 성과 균형성에 미치는 영향을 알아보기 위해 각 대상자가 백색 소음을 청취하기 전과 후 앉았다 일어서기 및 서있 기 동작 시 안정성과 균형성을 아래와 같이 분석하였다.

안정성의 경우 동작 중 신체질량중심 (center of mass $[\mathrm{CoM}])$ 에 관련된 변인들을 안정성을 대변하는 변인으로 선택하였으며, 균형성의 경우에는 동작 중 압력중심 (center of pressure $[\mathrm{CoP}]$ ) 에 관련된 변인들을 선택하 
였다(Winter, 2009; Ryu, 2010; Hamill \& Ryu, 2003; Huang, Lu, Chen, Wang \& Chou, 2008; Lugade, Lin \& Chou, 2011). 또한 기저면 중심과 $\mathrm{CoM}$ (BoS-CoM) 그리고 $\mathrm{CoP}-\mathrm{CoM}$ 의 시상면 (sagittal plane), 관상면(frontal plane)에서의 각도(angle)를 Matlab 2016a (Mathworks, USA)을 통하여 각각 계산 하였다(Figure 1).

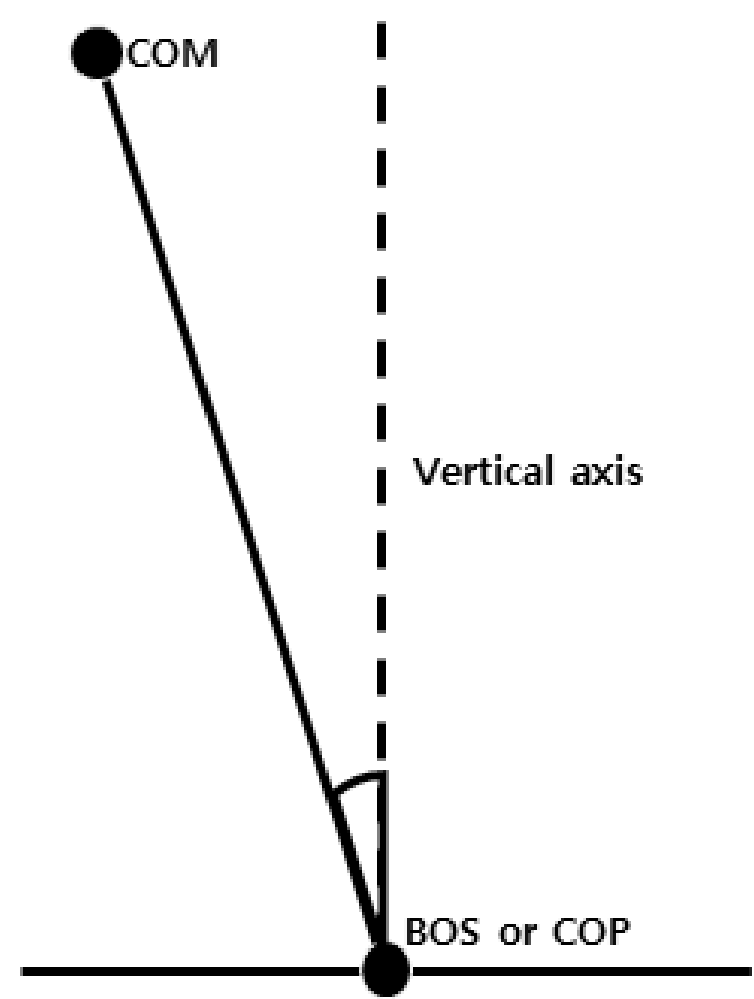

Fig. 1. Definition of BOS-COM and COP-COM angle

\section{통계처리}

본 연구에서는 백색 소음을 이용한 청각 자극 전·후, 만성 뇌졸증 환자의 앉았다 일어서기 및 서있기 동작 시 안정성과 균형성의 차이를 알아보기 위하여 대응표본 t검정(paired t-test)을 실시하였다. 이때, 통계적 유의 수준은 $\alpha=.05$ 로 설정하였다.

\section{연구결과}

본 연구에서는 백색 소음을 이용한 청각 자극이 만성 뇌 졸중 환자의 앉았다 일어서기 및 서있기 동작 시 안정성과 균형성에 미치는 영향을 살펴본 결과는 다음과 같다.

\section{안정성(stability)}

백색소음이 뇌졸중 환자의 안정성에 미치는 효과를 분 석한 결과, 백색 소음을 청취하기 전과 후 앉았다 일어서 기 및 서있기 동작 시 안정성, 균형성 변인에서의 모두 통 계적으로 유의한 차이는 나타나지 않았다(Table 1).

\section{균형성(balance)}

백색소음이 뇌졸중 환자의 균형성에 미치는 효과를 분 석한 결과, 눈감고 서있기 동작 시 백색 소음을 청취 전과 후 $\mathrm{CoP}$ 의 전·후 이동범위에서 통계적으로 유의한 차이가 나타났다 ( $p<.05$, Table 2). 또한, 눈뜨고 서있기와 눈감 고 서있기 동작 시 백색 소음을 청취 전과 후 $\mathrm{CoP}-\mathrm{CoM}$ 의 시상면에서의 각도가 모두 통계적으로 유의한 차이가 나 타났다( $p$ 〈.05, Table 2). 그러나 그 외 균형성 변인에서 는 통계적으로 유의한 차이가 나타나지 않았다(Table 2).

\section{논 의}

본 연구에서는 백색 소음을 이용한 청각 자극이 만성 뇌졸중 환자의 앉았다 일어서기 및 서있기 동작 시 안정 성과 균형성에 미치는 영향을 알아보고자 하였다.

$\mathrm{CoM}$ 은 안정성을 정량적으로 평가하기 위한 가장 대표 적인 변인 중 하나로써, 신체의 각 관절 중심점을 토대로 움직임 시 신체를 대변하는 하나의 점이다. 그리고 $\mathrm{BoS}$ 는 $\mathrm{CoM}$ 과 함께 안정성을 유지하기 위한 조건으로써 영 향을 미치는데, 본 연구에서 활용된 $\mathrm{BoS}-\mathrm{CoM}$ 의 각도는 단순하게 $\mathrm{BoS}$ 과 $\mathrm{CoM}$ 을 개별적으로 차이를 살펴보는 것 과는 달리 신체적인 특징을 일반화하기 위한 별도의 과정 을 요구하지 않기 때문에 보다 안정성을 살펴보기에 보다 적합한 변인이라 할 수 있다(Lugade et al., 2011). 
Table 1. Mean \pm standard deviation of stability variables and paired t-test results before and after white noise stimulus.

\begin{tabular}{|c|c|c|c|c|}
\hline \multirow{2}{*}{ Variables } & \multirow{2}{*}{ Task } & \multicolumn{2}{|c|}{ White noise } & \multirow{2}{*}{ t-value ( $p$-value) } \\
\hline & & Before & After & \\
\hline \multirow{3}{*}{$\begin{array}{l}\text { CoM Range A-P } \\
(\mathrm{mm})\end{array}$} & Standing with eyes-closed & $6.02 \pm 1.42$ & $5.51 \pm 1.30$ & $1.50(.15)$ \\
\hline & Standing with eyes-open & $12.69 \pm 4.85$ & $12.57 \pm 4.06$ & $0.31(.76)$ \\
\hline & Sit-to-Stand & $43.79 \pm 15.16$ & $48.84 \pm 16.12$ & $-1.76(.10)$ \\
\hline \multirow{3}{*}{$\begin{array}{l}\text { CoM Range M-L } \\
(\mathrm{mm})\end{array}$} & Standing with eyes-closed & $4.80 \pm 2.33$ & $5.78 \pm 3.87$ & $-1.10(.29)$ \\
\hline & Standing with eyes-open & $3.92 \pm 3.21$ & $6.04 \pm 8.43$ & $-0.96(.35)$ \\
\hline & Sit-to-Stand & $28.60 \pm 9.25$ & $32.78 \pm 12.18$ & $-1.92(.08)$ \\
\hline \multirow{3}{*}{$\begin{array}{l}\text { CoM Sway area } \\
\left(\mathrm{mm}^{2} / \mathrm{s}\right)\end{array}$} & Standing with eyes-closed & $0.12 \pm 0.13$ & $0.11 \pm 0.09$ & $0.37(.72)$ \\
\hline & Standing with eyes-open & $0.06 \pm 0.06$ & $0.06 \pm 0.05$ & $-0.12(.91)$ \\
\hline & Sit-to-Stand & $3.16 \pm 2.58$ & $4.32 \pm 3.37$ & $-1.83(.09)$ \\
\hline \multirow{3}{*}{$\begin{array}{l}\text { BoS-CoM Angle } \\
\text { in Sagittal plane } \\
\text { (deg) }\end{array}$} & Standing with eyes-closed & $7.41 \pm 1.90$ & $6.87 \pm 2.03$ & $1.05(.31)$ \\
\hline & Standing with eyes-open & $7.48 \pm 1.89$ & $6.99 \pm 2.05$ & $1.00(.33)$ \\
\hline & Sit-to-Stand & $6.90 \pm 2.63$ & $6.59 \pm 2.79$ & $0.34(.74)$ \\
\hline \multirow{3}{*}{$\begin{array}{l}\text { BoS-CoM Angle } \\
\text { in Frontal plane } \\
\text { (deg) }\end{array}$} & Standing with eyes-closed & $5.08 \pm 1.98$ & $4.97 \pm 2.31$ & $0.35(.73)$ \\
\hline & Standing with eyes-open & $5.05 \pm 2.05$ & $4.85 \pm 2.19$ & $0.57(.57)$ \\
\hline & Sit-to-Stand & $6.44 \pm 2.64$ & $6.82 \pm 2.78$ & $-0.92(.37)$ \\
\hline
\end{tabular}

Table 2. Mean \pm standard deviation of balance variables and paired t-test results before and after white noise stimulus.

\begin{tabular}{|c|c|c|c|c|}
\hline \multirow{2}{*}{ Variables } & \multirow{2}{*}{ Task } & \multicolumn{2}{|c|}{ White noise } & \multirow{2}{*}{ t-value ( $p$-value } \\
\hline & & Before & After & \\
\hline \multirow{3}{*}{$\begin{array}{l}\text { CoP Range A-P } \\
(\mathrm{mm})\end{array}$} & Standing with eyes-closed & $35.22 \pm 12.89$ & $29.49 \pm 11.67$ & $2.35(.03)^{*}$ \\
\hline & Standing with eyes-open & $27.19 \pm 9.81$ & $24.10 \pm 6.71$ & $1.22(.24)$ \\
\hline & Sit-to-Stand & $68.20 \pm 10.89$ & $70.52 \pm 11.02$ & $-0.60(.56)$ \\
\hline \multirow{3}{*}{$\begin{array}{c}\text { CoP Range M-L } \\
(\mathrm{mm})\end{array}$} & Standing with eyes-closed & $15.89 \pm 8.43$ & $17.10 \pm 9.22$ & $-0.58(.57)$ \\
\hline & Standing with eyes-open & $14.62 \pm 8.20$ & $16.91 \pm 20.62$ & $-0.43(.67)$ \\
\hline & Sit-to-Stand & $88.28 \pm 41.65$ & $84.78 \pm 39.40$ & $0.29(.78)$ \\
\hline \multirow{3}{*}{$\begin{array}{l}\text { CoP Sway area } \\
\left(\mathrm{mm}^{2} / \mathrm{s}\right)\end{array}$} & Standing with eyes-closed & $368.21 \pm 163.34$ & $339.60 \pm 130.84$ & $0.97(.35)$ \\
\hline & Standing with eyes-open & $369.56 \pm 165.04$ & $373.56 \pm 187.37$ & $-0.09(.93)$ \\
\hline & Sit-to-Stand & $401.95 \pm 147.52$ & $404.26 \pm 204.34$ & $-0.07(.95)$ \\
\hline \multirow{3}{*}{$\begin{array}{l}\text { CoP Velocity A-P } \\
(\mathrm{mm} / \mathrm{s})\end{array}$} & Standing with eyes-closed & $580.00 \pm 125.52$ & $571.23 \pm 136.20$ & $0.31(.76)$ \\
\hline & Standing with eyes-open & $583.38 \pm 121.93$ & $592.08 \pm 157.38$ & $-0.24(.81)$ \\
\hline & Sit-to-Stand & $623.23 \pm 123.29$ & $640.15 \pm 243.09$ & $-0.40(.69)$ \\
\hline \multirow{3}{*}{$\begin{array}{l}\text { CoP Velocity M-L } \\
(\mathrm{mm} / \mathrm{s})\end{array}$} & Standing with eyes-closed & $590.12 \pm 154.37$ & $563.04 \pm 122.61$ & $1.00(.33)$ \\
\hline & Standing with eyes-open & $587.97 \pm 140.54$ & $582.73 \pm 143.69$ & $0.19(.86)$ \\
\hline & Sit-to-Stand & $597.43 \pm 129.04$ & $592.58 \pm 124.78$ & $0.25(.81)$ \\
\hline \multirow{3}{*}{$\begin{array}{l}\text { CoP-CoM Angle } \\
\text { in Sagittal plane } \\
\text { (deg) }\end{array}$} & Standing with eyes-closed & $5.05 \pm 1.70$ & $3.87 \pm 1.60$ & $2.30(.04)^{*}$ \\
\hline & Standing with eyes-open & $5.07 \pm 1.73$ & $3.82 \pm 1.66$ & $2.34(.03)^{*}$ \\
\hline & Sit-to-Stand & $5.20 \pm 1.99$ & $4.47 \pm 2.46$ & $0.96(.35)$ \\
\hline \multirow{3}{*}{$\begin{array}{l}\text { CoP-CoM Angle } \\
\text { in Frontal plane } \\
(\text { deg })\end{array}$} & Standing with eyes-closed & $4.69 \pm 1.31$ & $4.63 \pm 1.37$ & $0.21(.84)$ \\
\hline & Standing with eyes-open & $4.68 \pm 1.30$ & $4.59 \pm 1.37$ & $0.29(.78)$ \\
\hline & Sit-to-Stand & $6.20 \pm 2.02$ & $6.13 \pm 1.73$ & $0.19(.86)$ \\
\hline
\end{tabular}


본 연구에서는 백색소음의 청취 여부에 따라 앉았다 일어서기 및 서있기 동작 시 안정성의 차이가 나타나지 않았다(Table 1). 선행연구를 통해 백색소음은 인지 행 동 감각 및 기능의 향상을 도모하고, 집중력을 강화하여 행동에 대한 실수를 감소시킬 수 있다고 보고되어왔고, 이는 직접적인 능력의 향상을 대변하는 균형성과 달리, 움직임을 수행하는 근본적인 전략을 대변하는 안정성에 는 크게 영향을 주지 못했다(Carlson et al., 1997; H erweg \& Bunzeck, 2015). 또한, 비교적으로 정적인 동작에 해당하는 앉았다 일어서기와 눈뜨고, 눈감고 서 있기와 같은 동작은 안정성에 있어서 영향을 미치는 기 저면, 신체질량 중심의 위치 및 높이가 크게 변화하지 않기 때문에 이와 같은 결과를 나타낸 것으로 판단된다.

$\mathrm{CoP}$ 는 균형성, 즉 자세제어 능력을 평가하기 위한 지 표로써 다양하게 활용되어 왔으며, 이는 지면 그리고 지 면과 접촉하고 있는 신체의 분절 사이에서 발현되는 지 면반력의 중심위치를 나타내는 하나의 위치이다(Doyl e, Hsiao-Wecksler, Ragan \& Rosengren, 2007). 그리고 균형성을 평가하는데 있어서 $\mathrm{CoP}$ 의 속도는 균 형을 유지하기 위해 사용되는 근육의 활동량 (muscle a ctivation)을 간접적으로 살펴볼 수 있는 변인으로써 제 시되어 왔다(Doyle et al., 2007; Ryu, 2010; Ryu, Yoo, Park \& Yoon, 2012; Verkindt, Dalleau, Le royer \& Allard, 2009). 또한 $\mathrm{CoP}-\mathrm{CoM}$ 각도는 정 적·동적 균형성을 측정하는 변인으로 시상면 각도는 활 동수준을 나타내고, 관상면 각도는 낙상 위험도를 판단 하는 기준으로 사용된다(Huang et al., 2008; Kerwi n \& Trewartha, 2001; Lee \& Chou, 2006; Yoo et al., 2014).

본 연구에서는 백색소음 청취 후 눈감고 서있기 동작 시 $\mathrm{CoP}$ 전·후 범위가 통계적으로 유의하게 약 $16 \%$ 그 리고 $\mathrm{CoP}-\mathrm{CoM}$ 의 시상면에서의 각도가 약 $23 \%$ 감소 하였으며, 눈 뜨고 서있기 동작 시 $\mathrm{CoP}-\mathrm{CoM}$ 의 시상면 에서의 각도가 통계적으로 유의하게 약 $25 \%$ 감소하였 다( $p<.05$, Table 2). 이와 같은 결과는 백색 소음을 통 한 청각 자극이 집중력, 인지 및 환경에 대한 정보 습득
능력에 긍정적인 영향을 미친 결과물로써 판단해 볼 수 있다. 특히, $\mathrm{CoP}$ 의 전·후 범위의 감소는 만성 뇌졸중으 로 인한 편마비와 직립자세에서의 비교적 작은 기저면 (base of support $[\mathrm{BoS}]$ )로 인해 증가하는 전방 혹은 후방으로의 낙상에 대한 위험도를 줄였다는 측면에서 보 다 큰 의미를 부여할 수 있으며, $\mathrm{CoP}-\mathrm{CoM}$ 의 시상면에 서의 각도 역시 이와 같은 맥락에서 그 의미를 가질 수 있을 것으로 보인다. 그러나 앉았다 일어서기 동작 시 모든 변인에서 통계적으로 유의한 차이가 나타나지 않은 이유를 살펴보면, 본 연구 결과가 앉았다 일어서기 동작 시 백색소음을 이용한 청각 자극의 효과를 확인 할 수 없 었고, 눈뜨고, 눈감고 서있기 동작 시에서만 통계적으로 유의한 차이가 나타났다. 특히, 눈감고 서있기 동작 시 $\mathrm{CoP}$ 의 단일 움직임에서 그 효과가 두드러졌다는 점에 주목할 필요가 있다. 백색소음이란, 특정 잡음을 통해 근본적으로 집중력과 관련하여 문제를 해결하고, 인지적 인 정보를 탐지하는데 도움을 준다고 알려져 있다. 따라 서 백색소음을 청취하는 환경 혹은 청취 후 과업을 수행 하는 환경 및 난이도 등과 같은 외적인 요인들이 이러한 효과에 영향을 충분히 미칠 수 있다. 실제, 선행연구들 을 통해 인간은 다양한 과업을 수행 할 때 행동에 대한 오류가 많이 발생된다고 보고한 바 있으며, 이는 추가적 인 자극에 대한 영향을 증감시킬 수 있다(Skaugset et al., 2016; Hsu, 2014; Stelzel et al., 2018). 본 연구 결과를 통해 백색소음은 뇌졸중 환자의 집중력과 관련한 인지 행동의 개선을 가져올 수는 있지만, 정적인 움직임에 그 효과가 제한되었다. 따라서 동적인 움직임 에서는 백색소음을 통한 청각 자극의 효과가 제한적으로 나타날 수 있다는 것을 예상해 볼 수 있다.

뇌졸중 환자의 독립적인 일상생활을 위해 백색소음을 적용하는 것은 본 연구결과를 통해 전·후 움직임에 대한 균형성 향상시키는 효과를 나타낸 것을 검증할 수 있었 다. 그 효과가 정적인 동작에서 그리고 보다 집중할 수 있는 환경에서 더 두드러지는 것을 고려했을때, 뇌졸중 환자의 재활 및 일상생활 시 정적인 움직임에 대한 균형 성을 향상시키기 위한 자극으로 활용될 수 있다고 판단 
된다. 또한, 본 연구 결과를 바탕으로 앉았다 일어서기 외 보행과 같은 반복적인 움직임 구사하는 동작 시 그 효 과를 살펴본다면 또 다른 결과를 나타낼 여지가 남아있 다. 따라서 향후 연구에서는 보다 반복적이고 기능적인 움직임에 있어서의 집중을 요구하는 과제을 통한 분석이 필요할 것으로 판단된다.

\section{결론 및 제언}

본 연구는 백색 소음을 이용한 청각 자극이 만성뇌졸 중 환자의 앉았다 일어서기 및 서있기 동작 시 안정성과 균형성에 미치는 영향을 알아보기 위해 진행되었다. 본 연구 결과, 백색 소음을 통한 청각 자극이 눈뜨고 서있기 동작 시 균형성 변인인 $\mathrm{CoP}-\mathrm{CoM}$ 의 시상면에서의 각도 가 통계적으로 유의하게 감소하였으며, 눈감고 서있기 동 작 시 $\mathrm{CoP}$ 전·후 이동범위와 $\mathrm{CoP}-\mathrm{CoM}$ 의 시상면에서의 각도가 통계적으로 유의하게 감소하였다. 이는 백색소음 을 통한 청각 자극이 뇌졸중 환자의 균형성에 긍정적인 영향을 미칠 수 있음을 시사한다. 그러나 본 연구에서는 그 효과가 정적인 동작인 서있기 동작에서만 나타났으며, 비교적 동적인 동작인 앉았다 일어서기에서는 나타나지 않았다. 또한, 외적인 자극을 최소화하고, 백색소음 청취 후 온전히 집중할 수 있는 환경에서 그 효과가 두드러지 는 것으로 나타났다. 따라서 백색 소음의 효과를 극대화 하고 실제 현장에 적용하기 위해서는 단순히 백색 소음의 적용 여부 뿐 만아니라, 적용환경에 대한 통제가 필요할 것으로 생각된다. 또한, 추후 보다 반복적이고, 기능적인 동작을 통한 검증을 통해 백색 소음을 통한 청각 자극의 효과를 살펴볼 필요가 있다고 판단된다.

\section{참고문헌}

Antić, S., Galinović, I., Lovrenčić-Huzjan, A., Vuković, V., Jurašić, M. J., \& Demarin, V. (2008). Music as an auditory stimulus in stroke patients. Collegium Antropologicum, 32(1), 19-23.

Buurke, J. H., Nene, A. V., Kwakkel, G., Erren-Wolters, V., IJzerman, M. J., \& Hermens, H. J. (2008). Recovery of gait after stroke: what changes?. Neurorehabilitation and Neural Repair, 22(6), 676-683.

Carlson, S., Rämä, P., Artchakov, D., \& Linnankoski, I. (1997). Effects of music and white noise on working memory performance in monkeys. Neuroreport, 8(13), 2853-2856.

Carter, B. (2013). Op Amps for Everyone. Newnes, 229-230.

Cha, Y., Kim, Y., \& Chung, Y. (2014). Immediate effects of rhythmic auditory stimulation with tempo changes on gait in stroke patients. Journal of Physical Therapy Science, 26(4), 479-482.

Dovat, L., Lambercy, O., Gassert, R., Maeder, T., Milner, T., Leong, T. C., \& Burdet, E. (2008). HandCARE: a cable-actuated rehabilitation system to train hand function after stroke. IEEE Transactions on Neural Systems and Rehabilitation Engineering, 16(6), 582-591.

Doyle, R. J., Hsiao-Wecksler, E. T., Ragan, B. G., \& Rosengren, K. S. (2007). Generalizability of center of pressure measures of quiet standing. Gait \& Posture, 25(2), 166-171.

Genthon, N., Vuillerme, N., Monnet, J. P., Petit, C., \& Rougier, P. (2007). Biomechanical assessment of the sitting posture maintenance in patients with stroke. Clinical Biomechanics, 22(9), 1024-1029.

Hamil, J., \& Ryu, J. S. (2003). Experiment in Sport Biomechanics. Seoul: Daehan Media.

Helps, S. K., Bamford, S., Sonuga-Barke, E. J., \& Söderlund, G. B. (2014). Different effects of adding white noise on cognitive performance of sub-, normal and super-attentive school children. PLoS One, 9(11), e112768.

Herweg, N. A., \& Bunzeck, N. (2015). Differential effects of white noise in cognitive and perceptual tasks. Frontiers in Psychology, 6, 1639.

Hsu, W. L. (2014). Adaptive postural control for joint immobilization during multitask performance. PloS one, 9(10), e108667.

Huang, S. C., Lu, T. W., Chen, H. L., Wang, T. M., \& Chou, L. S. (2008). Age and height effects on the center of mass and center of pressure inclination angles during obstacle-crossing. Medical Engineering \& Physics, 30(8), 968-975.

Hwang, J. H., Li, C. W., Wu, C. W., Chen, J. H., \& Liu, T. C. (2007). Aging effects on the activation of the auditory cortex during binaural speech listening in white noise: an fMRI study. Audiology and Neurotology, 12(5), 285-294.

Kerwin, D. G., \& Trewartha, G. (2001). Strategies for maintaining a 
handstand in the anterior-posterior direction. Medicine and Science in Sports and Exercise, 33(7), 1182-1188.

Ko, B. W., Lee, H. Y., \& Song, W. K. (2016). Rhythmic auditory stimulation using a portable smart device: short-term effects on gait in chronic hemiplegic stroke patients. Journal of Physical Therapy Science, 28(5), 1538-1543.

Krawczyk, M., Szczerbik, E., \& Syczewska, M. A. Ł. G. O. R. Z. A. T. A. (2014). The comparison of two physiotherapeutic approaches for gait improvement in sub-acute stroke patients. Acta of Bioengineering and Biomechanics, 16(1), 11-18.

Lee, H. J., \& Chou, L. S. (2006). Detection of gait instability using the center of mass and center of pressure inclination angles. Archives of Physical Medicine and Rehabilitation, 87(4), 569-575.

Lugade, V., Lin, V., \& Chou, L. S. (2011). Center of mass and base of support interaction during gait. Gait \& Posture, 33(3), 406-411.

Macko, R. F., Haeuber, E., Shaughnessy, M. A. R. I. A. N. N. E., Coleman, K. L., Boone, D. A., Smith, G. V., \& Silver, K. H. (2002). Microprocessor-based ambulatory activity monitoring in stroke patients. Medicine and Science in Sports and Exercise, 34(3), 394-399.

Mainka, S., Wissel, J., Völler, H., \& Evers, S. (2018). The use of rhythmic auditory stimulation to optimize treadmill training for stroke patients: a randomized controlled trial. Frontiers in Neurology, 9, 755.

Nadeau, S., Betschart, M., \& Bethoux, F. (2013). Gait analysis for poststroke rehabilitation: the relevance of biomechanical analysis and the impact of gait speed. Physical Medicine and Rehabilitation Clinics, 24(2), 265-276.

Peurala, S. H., Könönen, P., Pitkaenen, K., Sivenius, J., \& Tarkka, I. M. (2007). Postural instability in patients with chronic stroke. Restorative Neurology and Neuroscience, 25(2), 101-108.

Ryu, J. S. (2010). Effects of high-heeled shoe with different height on the balance during standing and walking. Korean Journal of Sport Biomechanics, 20(4), 479-486.

Ryu, J. S., Yoo, S. H., Park, S. K., \& Yoon, S. H. (2012). Comparisons between skilled and less-skilled players' balance in hakdariseogi. Korean Journal of Sport Biomechanics, 22(1), 55-63.

Sheean, G. (2002). The pathophysiology of spasticity. European Journal of Neurology, 9, 1-4.
Sheean, G., \& McGuire, J. R. (2009). Spastic hypertonia and movement disorders: pathophysiology, clinical presentation, and quantification. The journal of Injury, Function and Rehabilitation, 1(9), 827-833.

Silver, K. H., Macko, R. F., Forrester, L. W., Goldberg, A. P., \& Smith, G. V. (2000). Effects of aerobic treadmill training on gait velocity, cadence, and gait symmetry in chronic hemiparetic stroke: a preliminary report. Neurorehabilitation and Neural Repair, 14(1), 65-71.

Skaugset, L. M., Farrell, S., Carney, M., Wolff, M., Santen, S. A., Perry, M., \& Cico, S. J. (2016). Can you multitask? Evidence and limitations of task switching and multitasking in emergency medicine. Annals of Emergency Medicine, 68(2), 189-195.

Söderlund, G. B., Sikström, S., Loftesnes, J. M., \& Sonuga-Barke, E. J. (2010). The effects of background white noise on memory performance in inattentive school children. Behavioral and Brain Functions, 6(1), 55.

Song, G. B., \& Ryu, H. J. (2016). Effects of gait training with rhythmic auditory stimulation on gait ability in stroke patients. Journal of Physical Therapy Science, 28(5), 1403-1406.

Stelzel, C., Bohle, H., S chauenburg, G., Walter, H., Granacher, U., Rapp, M. A., \& Heinzel, S. (2018). Contribution of the lateral prefrontal cortex to cognitive-postural multitasking. Frontiers in Psychology, 9, 1075.

Thaut, M. H., \& Abiru, M. (2010). Rhythmic auditory stimulation in rehabilitation of movement disorders: a review of current research. Music Perception, 27(4), 263-269.

van Vilet, P. M., \& Wulf, G. (2006). Extrinsic feedback for motor learning after stroke: what is the evidence?. Disability and Rehabilitation, 28(13-14), 831-840.

Verkindt, C., Dalleau, G., Leroyer, P., \& Allard, P. (2009). Quiet standing balance in pre-adolescent girls and woman. International Society of Biomechanics XXIInd Congress Proceedings.

Winter, D. A. (2009). Biomechanics and motor control of human movement. New York, NY: John Wiley.

Yoo, S. H., Gil, H. J., Kim, J. N., Ha, S. H., Ryu, J. S., Park, S. K., \& Yoon, S. H. (2014). The effects of sports talented exercise program on single leg standing balance. The Korean Journal of Physical Education, 53(3), 721-730. 


\title{
백색소음을 이용한 청각 자극이 만성 뇌졸중 환자의 앉았다 일어서기 및 서있기 동작 시 안정성과 균형성에 미치는 영향
}

\author{
임희성 ${ }^{1}$, 박상헌 ${ }^{1}$, 김주년 ${ }^{2}$ \\ 1한국체육대학교 연구원 \\ 2한국스포츠정책과학원 분석연구원
}

[목적〕 본 연구의 목적은 백색 소음을 이용한 청각 자극이 만성 뇌졸중 환자의 앉았다 일어서기 (sit-to-stand) 및 서있기(standing) 과제 시 안정성과 균형성에 미치는 영향을 조사하는 것이다. 〔방법〕 만성 뇌졸중 환자 18 명이 본 연구에 참여하였으며, 백색소음을 청취하기 전·후로 앉았다 일어서기와 눈뜨고 서있기, 눈감고 서있기 과제를 실시하였다. 각 과제 수행 시, 백색소음 자극 전·후 안정성 및 균형성을 평가하 기 위해, 적외선 카메라 8 대와 지면반력기 1 대를 사용하였다. 〔결과〕 모든 과제에서 백색소음 자극 전·후에 유의한 차이는 나타나지 않았다. 반면, 눈감고 서있기 과제 시 백색소음 자극 후 $\mathrm{CoP}$ 의 전·후 이동범위가 유의 하게 감소하였으며 $(p<.05)$, 눈뜨고 서있기와 눈감고 서있기 과제 시 $\mathrm{CoP}-\mathrm{CoM}$ 의 시상면 각도가 백색소음 자극 후 유의하게 감소하였다 $(p<.05)$. 〔결론〕 백색소음을 사용한 청각 자극은 만성 뇌졸중 환자의 균형성을 향상시키기 때문에, 뇌졸중 환자의 독립적인 일상생활에 도움이 될 것으로 생각된다.

주요어: 뇌졸중, 백색소음, 청각 자극, 안정성, 균형성 